\title{
ME LLAMO RIGOBERTA MENCHÚ Y ASÍ ME NACIÓ LA CONCIENCIA E EXCLUSÃO SOCIAL: A LÍNGUA ESPANHOLA COMO DISPOSITIVO DE PODER
}

\author{
ME LLAMO RIGOBERTA MENCHÚ Y ASÍ ME NACIÓ LA \\ CONCIENCIA AND SOCIAL EXCLUSION: SPANISH AS A \\ POWER DEVICE
}

Fernando Zolin-Vesz ${ }^{*}$

Sandra Leite dos Santos ${ }^{* *}$

\begin{abstract}
Resumo: Neste artigo, investigamos, por meio da obra Me llamo Rigoberta Menchú y así me nació la conciencia, de Elizabeth Burgos, publicada em 1985, a atuação da língua espanhola como dispositivo de poder que conduz à exclusão social das comunidades indígenas na Guatemala. O referencial teórico baliza-se no contexto sócio-histórico guatemalteco, no que se refere à herança linguístico-colonial do país, apoiado em Böckler (2001), Böckler e Herbert (2002), Castillo, Paz e Quemé (2005), e Prenafeta (2014), em diálogo com os conceitos de dispositivo e relações de poder (FOUCAULT, 2012; MACHADO, 2012). Os resultados apontam para a língua espanhola como um dispositivo de poder que define quem está incluído/excluído socialmente, contribuindo, assim, para que muitas comunidades indígenas se situem à margem da sociedade guatemalteca.
\end{abstract}

Palavras-chave: língua espanhola. dispositivo de poder. exclusão social.

\begin{abstract}
This paper aims at investigating the role of Spanish as a power device that leads to the social exclusion of Guatemalan native communities by focusing on Elizabeth Burgos' Me llamo Rigoberta Menchú y así me nació la conciencia, which was published in 1985. The theoretical background is based on the sociohistorical context of Guatemala, in particular the linguistic and colonial heritage of the country (BÖCKLER, 2001; BÖCKLER \& HERBERT, 2002; CASTILLO; PAZ \& QUEMÉ, 2005; PRENAFETA, 2014), in dialogue with the Foucauldian concepts of device and relation of power (FOUCAULT, 2012; MACHADO, 2012). Results suggest that Spanish performs as a power device which defines who is included and who is excluded in society. This seems to contribute to position many native communities aside from the Guatemalan society.
\end{abstract}

Key words: Spanish. power device. social exclusion.

\section{Considerações iniciais}

Rigoberta Menchú Tum é uma indígena guatemalteca da etnia maya-quiché que alcançou notoriedade devido à publicação, em 1985, de sua biografia, intitulada $M e$ llamo Rigoberta Menchú y así me nació la conciencia, produzida com a colaboração de Elizabeth Burgos. A obra narra a situação de injustiça social que cercava Menchú e as

\footnotetext{
*Doutor em Letras e Linguística. Universidade Federal de Mato Grosso (UFMT). E-mail: fernando_vesz@hotmail.com

${ }^{* *}$ Mestre em Estudos de Linguagem. Secretaria de Estado de Educação de Mato Grosso (SEDUC-MT). Email: sanlei@hotmail.com
} 
comunidades indígenas da Guatemala, cujas relações de poder, que a originam, sugerem a língua espanhola como dispositivo empregado para marginalizar e excluir.

Conforme Menchú, grande parte da população indígena guatemalteca não possuía conhecimento da língua espanhola, imposta à Guatemala pela Espanha ainda no período colonial, e tomada, portanto, como sinônimo de idioma oficial do país, o que contribuía decisivamente para que se constituísse como um dispositivo de segregação e de exclusão social das comunidades indígenas. A função antes exercida pelo colonizador espanhol agora está a cargo do ladino, termo empregado para designar os guatemaltecos frutos da "miscigenação" entre os colonizadores europeus e os indígenas, que continua valendo-se da língua considerada oficial para perpetuar a exclusão das comunidades indígenas (PRENAFETA, 2014).

O intuito desta investigação é, portanto, analisar a atuação da língua espanhola como um dispositivo de poder que leva à exclusão social relatada na referida obra. Embora a obra seja marcada pela contestação tanto da autoria, uma vez que, conforme apontamos acima, foi escrita por Elizabeth Burgos, quanto da veracidade dos fatos narrados pela indígena, para Beverley (2012) essa discussão se apresenta como mais ampla, ou seja, proporciona querelas acerca da verdade (única e universal) e de quem está autorizado a pronunciá-la, em especial na construção dos relatos sociais de vida daqueles que seguem escamoteados pelas heranças do processo colonial. Por esse viés, a biografia de Menchú se coloca como uma janela que expõe ao mundo as mazelas, produzidas como resultado do processo colonial e ainda hoje vividas pelos povos indígenas, não apenas da Guatemala, mas das Américas, de feitio que todo e qualquer privilégio excludente, herdado do processo colonial, possa ser questionado (cf. ZOLINVESZ; SANTOS, 2018).

Inicialmente, discutimos o contexto sócio-histórico da Guatemala, abordando alguns aspectos da colonização do país pela Espanha, em especial os linguísticos, conforme Böckler (2001), Böckler e Herbert (2002), Castillo, Paz e Quemé (2005) e Prenafeta (2014). Em seguida, trazemos à baila o conceito de dispositivo de poder (FOUCAULT, 2012; MACHADO, 2012). Por fim, analisamos excertos da biografia de Rigoberta Menchú, buscando evidenciar, em sua narrativa, a constituição do espanhol como dispositivo de exclusão social e, por conseguinte, o estabelecimento das relações de poder por meio do (não) conhecimento da língua.

\section{A língua espanhola como herança colonial}

O processo de colonização imposto à Guatemala pela Espanha apresenta resquícios que, ainda hoje, acometem os indígenas guatemaltecos (cf. BÖCKLER, 2001; BÖCKLER; HERBERT, 2002). Böckler (2001) ressalta que, no decorrer do período colonial, os índios foram obrigados a viver separados dos espanhóis. Dessa forma, suas moradias se situavam em locais periféricos: "nos perímetros urbanos se localizava a população autóctone em bairros segregados, dos quais podiam sair, somente, para realizar os trabalhos que lhes eram encomendados, assim como para 
assistir às cerimônias religiosas cristãs ${ }^{1}$ " (BÖCKLER, 2001, p. 13). Aos índios, portanto, não era dado o direito de viver em locais mais urbanizados: sua presença na cidade, conforme aponta o autor, era restrita.

Ainda de acordo com Böckler (2001), as relações sociais cotidianas entre as comunidades indígenas e os colonizadores espanhóis nascem marcadas pelas desigualdades sociais em todos os níveis, que se materializam, principalmente, na língua, afetando de maneira significativa os indígenas. O espanhol, imposto pelo colonizador europeu, adquire o estatuto de língua oficial, e tanto as línguas indígenas quanto seus falantes são desconsiderados, passando a ocupar posição inferior na sociedade. Como apontam Castillo, Paz e Quemé (2005), a língua espanhola, ao longo da história da Guatemala, é um dispositivo empregado com constância para estabelecer os que estão incluídos e os que estão excluídos socialmente: muitos indígenas ainda vivem à margem da sociedade pelo fato de não possuírem conhecimento da língua (cf. PRENAFETA, 2014).

Assim, a língua prescrita pelo colonizador, alçada ao posto de oficial do país, prevalece, preservando relações de marginalização e de exclusão das comunidades indígenas, as quais, conforme apontamos anteriormente, estabeleceram-se desde o período colonial. Nessa seara, Menchú passa a entender a aprendizagem da língua espanhola como necessidade, como forma de sobrevivência frente a uma sociedade em que não está incluída.

\section{3. $O$ conceito de dispositivo de poder}

O conceito de dispositivo de poder está relacionado com dois outros pontos debatidos por Michel Foucault: poder e relações de poder. Para o autor, não existe algo unitário e global chamado poder, mas, como nos adverte Machado (2012), trata-se de "uma prática social e, como tal, constituída historicamente" (MACHADO, 2012, p. X). Desse modo, para além de algo estático e único, a definição de poder abrange inúmeras formas, nas mais variadas situações, ou seja, está presente em todas as nossas práticas sociais e não pertence especificamente a um grupo ou a uma localidade determinada. $\mathrm{O}$ poder, portanto, é algo que se exerce por intermédio de inúmeros pontos e em meio a relações móveis (cf. FOUCAULT, 2012). Essas relações são as práticas sociais pelas quais o poder se manifesta, estabelecendo, assim, relações desiguais de dependência entre indivíduos e/ou grupos sociais - por isso o autor as denomina relações de poder.

Assim, "as relações de poder são uma relação desigual e relativamente estabilizada de forças" (FOUCAULT, 2012, p. 250), o que resulta, conforme o autor, em uma "diferença de potencial". No contexto sócio-histórico da Guatemala, essas relações se encontram bem definidas, pois estabelecem a diferença entre aquele que é acolhido pela sociedade e o que dela é marginalizado e excluído. Essa inclusão/exclusão se encontra alicerçada em dispositivos: as relações de poder são, por conseguinte,

\footnotetext{
${ }^{1}$ No original, "en los perímetros urbanos se ubicó a la población autóctona en barrios segregados, de los cuales sólo podía salir, para efectuar los trabajos que se encomendaban, así como para asistir a las ceremonias religiosas cristianas" (BÖCKLER, 2001, p. 13).
} 
exercidas por dispositivos de poder. Como destaca Foucault (2012), o poder funciona como uma rede de dispositivos ou mecanismos da qual não há escapatória. É algo que se interpõe a todas as nossas atividades em sociedade, abrangendo tudo e todos. Assim sendo, o autor define dispositivo como

um conjunto decididamente heterogêneo que engloba discursos, instituições, organizações arquitetônicas, decisões regulamentares, leis, medidas administrativas, enunciados científicos, proposições filosóficas, morais, filantrópicas. Em suma, o dito e o não dito são os elementos do dispositivo. $\mathrm{O}$ dispositivo é a rede que se pode estabelecer entre estes elementos. (FOUCAULT, 2012, p. 244)

Conforme propomos neste artigo, em Me llamo Rigoberta Menchú y así me nació la conciencia, o (não) conhecimento do espanhol - alçado ao posto de língua oficial da Guatemala pelo processo colonial - constitui um dispositivo de poder, uma vez que resulta de uma "diferença de potencial" a qual permite o processo de inclusão/exclusão na sociedade guatemalteca. O estabelecimento dessas relações de poder pode ser observado por meio da análise de excertos da biografia de Rigoberta Menchú, ponto desenvolvido na seção seguinte.

\section{A língua espanhola como dispositivo de exclusão social em Me llamo Rigoberta Menchú y así me nació la conciencia}

Nesta seção, analisamos cinco excertos, retirados da biografia de Menchú, em que as relações de poder, estabelecidas por meio do dispositivo língua, contribuem para marginalizar e excluir ainda mais as comunidades indígenas da Guatemala.

Conforme a narrativa de Menchú, a colheita de café, algodão e cana de açúcar, em latifúndios localizados na costa da Guatemala, é, em grande parte, o trabalho disponível para os indígenas. Em decorrência disso, necessitam deixar suas casas, ao menos quatro vezes ao ano, com a intenção de garantir a subsistência. A indígena reporta que os contratantes dessas empreitadas, de modo geral, também são índios que abandonam suas comunidades com o intuito de aprender espanhol a fim de trabalhar nas fazendas, principalmente como capatazes, o que lhes confere certa posição de superioridade em relação aos demais indígenas. Nessa condição, lançam mão do espanhol como dispositivo para a exploração dos indígenas contratados. $\mathrm{O}$ excerto 1 parece colaborar para a compreensão dessa função da língua como dispositivo de poder.

\section{Excerto 1}

[Los contratantes] Hablan español y es precisamente el acercamiento a los terratenientes, porque nosotros, los indígenas, no hablamos el español, entonces muchas veces nos engañan en todo y como no hablamos el español, no nos podemos quejar [...]. (BURGOS, 2011, p. 44)

Como é possível depreender do excerto, a língua espanhola constitui o principal instrumento por meio do qual os indígenas são enganados e explorados, ou melhor, o 
não conhecimento da língua permite que os indígenas sejam ludibriados em seus salários, nas contas feitas na fazenda, na pesagem das sacas colhidas e em tudo que seja possível diminuir seus rendimentos, como relata Menchú em outro momento. De modo imediato, conforme o excerto, o desconhecimento do espanhol impossibilita que os indígenas possam sequer reclamar das condições fraudulentas de trabalho. Portanto, o espanhol, catapultado à posição de língua oficial da Guatemala, parece funcionar como um dispositivo de poder empregado para conferir lugar de superioridade ao falante, mesmo que indígena, em detrimento do indígena não falante, de tal forma a relegá-lo à exploração e à marginalização. Como já antecipamos, é essa "diferença de potencial" (FOUCAULT, 2012, p. 250) que permite o processo de inclusão/exclusão na sociedade guatemalteca, e a língua espanhola parece funcionar decisivamente para o desenvolvimento desse processo.

No excerto 2, o espanhol adquire, uma vez mais, caráter de dispositivo de poder durante a narrativa de Menchú sobre sua mudança, aos treze anos de idade, para a casa de uma família ladina com o intuito de aprender a língua e ajudar financeiramente sua família. O desconhecimento das regras de formalidade da língua espanhola, no que tange ao uso das formas de tratamento utilizando os pronomes tú e usted, parece-nos evidenciar novamente a "diferença de potencial" entre as personagens.

\section{Excerto 2 \\ No teníamos que le decir una palabra, por ejemplo, de tú, sino que le teníamos que decir usted, porque eran respetados. Entonces, una vez, que a mí me costaba el castellano y apenas empezaba a hablar algunas palabras, yo quizá le dije tú a la señora. Casi me pega. Y me dijo: "Tú será tu madre. Tienes que respetarme tal como soy". (BURGOS, 2011, p. 123)}

A narrativa de Menchú sugere, outra vez, a perpetuação, herdada do período colonial imposto à Guatemala, da relação de superioridade do falante de espanhol - la señora - frente à posição de inferioridade de Menchú como não falante da língua. $\mathrm{O}$ uso "equivocado" dos pronomes pessoais tú e usted por Menchú parece-nos evidenciar a posição que cada personagem ocupa: falante de espanhol/não falante de espanhol, porquanto superior/inferior, não indígena/indígena, incluído/excluído, respectivamente. Essas posições, bem definidas, estabelecem-se por meio de relações de poder, em que a língua funciona como um gatilho, ou seja, um dispositivo que contribui para a demarcação do posicionamento social que cada personagem ocupa. Como bem la señora adverte Menchú, "tienes que respetarme tal como soy" - la señora, não indígena, falante de espanhol, incluída na sociedade; portanto, usted.

O excerto 3 contribui para reafirmar o papel do espanhol como dispositivo que aciona relações de poder: o não conhecimento da língua inviabiliza que Menchú possa reivindicar qualquer outro posicionamento social que não aquele imposto por la señora.

\section{Excerto 3}

Llegó un momento que en que me privó de hablar la señora con la muchacha y me dijo, no hables con la otra muchacha. Si hablas, te echo. Porque ella 
pensaba que la muchacha me estaba enseñando muchas cosas: cómo protestarle y lo que no le convenía (BURGOS, 2011, p. 123).

A preocupação, ante a possibilidade de que Menchú venha a aprender espanhol, por meio da interação com la otra muchacha da casa, parece-nos fomentar não apenas a possibilidade de contestação do tratamento dispensado pela señora, mas, principalmente, evidenciar como a língua espanhola funciona como um dispositivo que contribui para manter inalterável a "diferença de potencial" entre as personagens. Aprender espanhol poderia significar a possibilidade de Menchú tanto de discordar quanto de opor-se à demarcação social imposta pelas relações de poder que sustentam a sociedade guatemalteca (falante de espanhol/não falante de espanhol, superior/inferior, não indígena/indígena, incluído/excluído), materializada no excerto por meio da relação entre la señora e Menchú. A nosso ver, o excerto afigura-se exemplar para retratar a língua espanhola como dispositivo de poder que resulta na exclusão social das comunidades indígenas da Guatemala: o seu (não) conhecimento colabora categoricamente para o processo de inclusão ou exclusão social.

Como vimos abordando ao longo desta seção, no que diz respeito às comunidades indígenas da Guatemala, o espanhol parece ascender incessantemente o processo de exclusão social. No excerto 4, é o próprio Estado que parece incitar tal movimento: quando a comunidade de Menchú passa por constantes problemas em relação à posse de suas terras, o pai da indígena, que está à frente das negociações com as autoridades governamentais, encontra, mais uma vez, na língua espanhola, o dispositivo que se interpõe entre aqueles a que o Estado acolhe e aqueles que marginaliza e exclui.

\section{Excerto 4}

El gobernador no entiende la lengua del pueblo. Y el gobernador sólo cree cuando es un licenciado o un abogado el que está trabajando, y hablando. Porque a un indígena no lo acepta (BURGOS, 2011, p. 129).

No contexto sócio-histórico da Guatemala, o espanhol, imposto pelo colonizador europeu, adquiriu o estatuto de língua oficial, de modo que as línguas indígenas ocupassem posição inferior na sociedade. $\mathrm{O}$ excerto 4 parece atestar tal processo herdado do período colonial. Como Menchú relata, as autoridades governamentais não apenas desconhecem as línguas indígenas como também recusam-se a aceitar qualquer reivindicação sem a presença de advogados e intermediários que representem os indígenas. Portanto, o próprio Estado guatemalteco possui papel peremptório na constituição do espanhol como dispositivo de poder empregado para marginalizar e excluir as comunidades indígenas.

Já o excerto 5 contribui para reforçar, uma vez mais, a "diferença de potencial", resultante das relações de poder desiguais, que acometem os indígenas até mesmo em comparação com os ladinos, frutos da "miscigenação" entre os colonizadores europeus e os próprios indígenas. Sob o aval do Estado (conforme observamos no excerto 4), a 
língua espanhola funciona como um dispositivo hábil a acionar relações de poder que segregam inclusive os indígenas dos ladinos, apesar de ambos compartilharem situações análogas de pobreza e de exploração.

\section{Excerto 5}

Porque el ladino, a pesar de ser pobre, de ser explorado como nosotros, trata de ter un aliento más que el indígena [...] El ladino puede reclamar [...], pero el indígena no es capaz de hacer eso. El ladino tiene muchos recursos para hablar (BURGOS, 2011, p. 193).

O excerto nos parece apontar, novamente, para o papel do (não) conhecimento do espanhol na constituição das relações sociais de inferioridade que afligem os indígenas: o ladino, mesmo que se encontre em condições de vida similares, possui a vantagem do conhecimento da língua - "el ladino puede reclamar"; "el ladino tiene muchos recursos para hablar". Outra vez, a língua espanhola se afigura como um dispositivo de poder que colabora incisivamente para a exclusão das comunidades indígenas da Guatemala.

$\mathrm{Se}$, sob a perspectiva foucaultiana, todo exercício de poder instala um dispositivo, em Me llamo Rigoberta Menchú y así me nació la conciencia, a língua espanhola é um dos dispositivos que, na Guatemala, propaga relações desiguais de poder: a questão linguística está envolvida com os problemas sociais que assolam principalmente as comunidades indígenas. Situações de marginalização e de exclusão social se encontram ligadas ao não conhecimento desse dispositivo, bem como situações de acolhimento e de inclusão se vinculam ao conhecimento do mesmo dispositivo. Em última análise, relações de poder desiguais, que originam "diferença de potencial" por meio do dispositivo língua, parecem, portanto, constituir o cerne do processo sóciohistórico que produz a exclusão social das comunidades indígenas da Guatemala.

Por meio de sua biografia, Menchú traz à tona os efeitos desse processo, cujo desenvolvimento, imposto pelo colonizador europeu desde a invasão do território que, mais tarde, viria a ser denominado Guatemala, parece-nos centrar-se no espanhol como dispositivo de poder. Desse modo, o não conhecimento da língua compõe o mecanismo social empregado para discriminar, explorar e excluir as comunidades indígenas guatemaltecas, tática que se configura infinitamente não apenas a cada excerto analisado neste artigo, mas a cada capítulo da biografia de Menchú.

\section{Considerações finais - e se uma imagem vale mais do que mil palavras...}

No preâmbulo de Me llamo Rigoberta Menchú y así me nació la conciencia, Elizabeth Burgos nos adverte que "la historia de Rigoberta hace eco a la historia de todas las comunidades indígenas de América Latina”. Sendo assim, conforme observamos já na introdução deste artigo, entendemos a biografia de Menchú como uma janela que expõe as privações resultantes do processo colonial imposto por países 
europeus às Américas e que, ainda hoje, insistentemente desconsideram qualquer direito mínimo de inclusão social das comunidades indígenas, por meio de dispositivos de poder mais propensos a marginalizar e excluir. Além disso, a biografia nos parece oportunizar visibilidade a esses grupos sociais, historicamente marginalizados e excluídos.

Para aqueles que, ao se deparar com a biografia de Menchú, teimam em contestar a autoria da obra, bem como a veracidade dos fatos narrados pela indígena, ou ainda alegam que se trata de uma realidade particular da constituição do Estado da Guatemala e, desse modo, distante da nossa, convidamos a levar em consideração nosso contexto sócio-histórico também fruto de um processo colonial: quem está autorizado a construir os relatos sociais de vida daqueles que seguem escamoteados pelas desigualdades sociais herdadas desse processo colonial, que contribuem consideravelmente para os mais diversos quadros de exclusão social também em nosso país?

Para finalizar, considerando que uma imagem vale mais do que mil palavras, talvez a ilustração abaixo do Padre Antonio Vieira, centralizado em pé entre dois indígenas curvados, como em sinal de reverência, que se encontra no Museu do Forte do Presépio, na cidade de Belém, Estado do Pará, possa contribuir para os questionamentos que propomos com este artigo. Se jogue, leitor(a)! Pensar ainda é livre!

Figura 1 - Ilustração do Padre Antonio Vieira, do Museu do Forte do Presépio

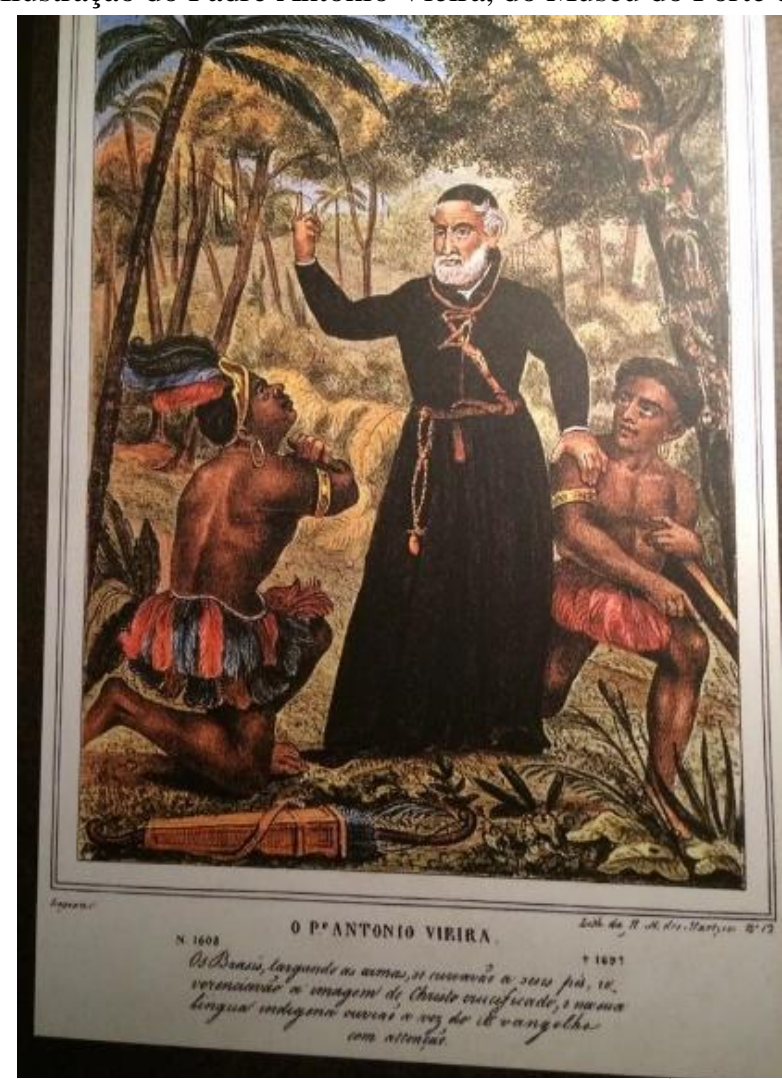

Fonte: Acervo dos autores (10 jul 2017)

\footnotetext{
${ }^{2}$ Agradecemos à Profa. Dra. Cristina Vasconcelos Porto, do Instituto de Letras e Comunicação da Universidade Federal do Pará, pelo envio da imagem.
} 


\section{Referências}

BEVERLEY, J. Subalternidad y testimonio: en diálogo con Me llamo Rigoberta Menchú y así me nació la conciencia, de Elizabeth Burgos (con Rigoberta Menchú). Nueva Sociedad, n. 238, 2012, p. 102-113.

BÖCKLER, C. G. Ri okel nqetamaj pa Iximulew. Cuando se quiebran los silencios. Lo que todos debemos saber de la historia de Guatemala. Ciudad de Guatemala: Cholsamaj, 2001.

BÖCKLER, C. G.; HERBERT, J. L. Guatemala: una interpretación histórico-social. Ciudad de Guatemala: Cholsamaj, 2002.

BURGOS, E. Me llamo Rigoberta Menchú y así me nació la conciencia. Ciudad del México: Siglo XXI, 2011. 20a. reimp.

CASTILlO, E. G.; PAZ, M. C.; QUEMÉ, J. C. Libro de texto universitario sobre historia de Guatemala: época Colonial, 1524-1821. PROGRAMA: Programa Universitario de investigación en Historia de Guatemala. Universidad de San Carlos de Guatemala, 2005.

FOUCAULT, M. Microfísica do poder. Tradução Roberto Machado. Rio de Janeiro: Graal, 2012.

MACHADO, R. Por uma genealogia do poder. In: FOUCAULT, M. Microfísica do poder. Tradução Roberto Machado. Rio de Janeiro: Graal, 2012, p. 7-23.

PRENAFETA, I. S. Guatemala: senda maya. Barcelona: Laertes, 2014.

ZOLIN-VESZ, F.; SANTOS, S.L. Possibilidades para a inclusão de literatura (não canônica) no ensino médio: Me llamo Rigoberta Menchú y así me nació la conciencia na sala de aula. Signo, v. 43, n. 78, 2018, p. 123-130.

Recebido em 28 de fevereiro de 2019

Aceito em 27 de abril de 2019 